\title{
Uso de vinhaça e impactos nas propriedades do solo e lençol freático
}

\author{
Mellissa A. S. da Silva ${ }^{1}$, Nori P. Griebeler ${ }^{2} \&$ Lino C. Borges ${ }^{3}$
}

\begin{abstract}
RESUMO
De maneira geral, a vinhaça apresenta elevadas concentrações de nitrato, potássio e matéria orgânica; sua utilização pode alterar as características do solo promovendo modificações em suas propriedades químicas, favorecendo o aumento da disponibilidade de alguns elementos para as plantas. Por outro lado, a vinhaça também pode promover modificações das propriedades físicas do solo, de duas formas distintas: essas alterações podem melhorar a agregação, ocasionando a elevação da capacidade de infiltração da água no solo e, consequentemente, aumentar a probabilidade de lixiviação de íons, de forma a contaminar as águas subterrâneas quando em concentrações elevadas, além de promover a dispersão de partículas do solo, com redução da sua taxa de infiltração de água e elevação do escoamento superficial, com possível contaminação de águas superficiais. Pelo fato de haver diferentes tipos de solo e composições de vinhaça, os resultados dos trabalhos são bastante variáveis; contudo, existe consenso de que sua disposição deve ser efetuada de acordo com a capacidade do solo em trocar e reter íons.
\end{abstract}

Palavras-chave: água subterrânea, contaminação, resíduo agroindustrial

\section{Use of stillage and its impact on soil properties and groundwater}

\begin{abstract}
Usually stillage presents high concentrations of nitrate, potassium and organic matter. Its utilization may change a soil's characteristics and modify its chemical properties, increasing the availability of some elements for plants. On the other hand, stillage may also promote change in physical properties of soil in two different ways: these changes can improve soil aggregation, increasing soil water infiltration capacity and, consequently, increasing leaching of ions, in such a way to contaminate the groundwater when in high concentrations, as well as to promote dispersion of soil particles, contributing for a decrease in its infiltration rate and elevation of runoff, with possible contamination of surface water. Due to the fact that there are different types of soil and stillage composition, the research results found are very variable, however, agreement exists that its application must be made according to cation exchange capacity of soil.
\end{abstract}

Key words: groundwater, contamination, agricultural residue

${ }^{1}$ Doutoranda do PPGA-EA/UFG. Bolsista CNPq. Rod. Goiânia-Nova Veneza, km zero, CP 131, CEP 74001-970. Goiânia, GO. Fone: (62) $3521-1542$. E-mail: melsoler@hotmail.com

2 EA/UFG, Goiânia, GO. E-mail: griebeler@yahoo.com.br

${ }^{3}$ Doutorando do PPGA-EA/UFG. Pesquisador da Agência Rural de Goiás. Rua Jornalista Geraldo Vale, n. 331, Setor Leste Universitário, CP 331, CEP 74610-060, Goiânia, GO. Fone: (62) 3201-8700. E-mail: linocborges@hotmail.com 


\section{INTRODUÇÃO}

Os solos apresentam diferentes capacidades de retenção de elementos orgânicos e inorgânicos. A retenção e a movimentação de elementos solúveis são determinadas pela textura e porosidade do solo e pela característica de cada superfície coloidal, a qual influenciará na solubilidade e troca de íons por processos de adsorção-dessorção, devido à complexação e reação redox dos elementos ativos na solução do solo, sendo que essas propriedades são fortemente influenciadas pela quantidade de matéria orgânica existente e pela drenagem do solo.

Em determinadas circunstâncias, as características da vegetação influenciam a dinâmica da água, notadamente como fator de redução da evaporação, aumento da capacidade de infiltração e proteção do solo contra os efeitos danosos provocados pelo impacto das gotas de chuva, evitando carregamento e posterior sedimentação de partículas nas partes mais baixas do terreno, principalmente para os cursos d’água alterando, sobremaneira, sua qualidade. A presença de cobertura vegetal favorece, ainda, a implementação da qualidade física do solo uma vez que possibilita melhoria na agregação e elevação da resistência a erosão hídrica, contribuindo para elevar seu potencial agrícola porém quaisquer alterações na composição química e estrutura do solo serão refletidas nas características físicas e químicas da água, tanto superficial quanto subterrânea; assim, ocorrendo aumento da infiltração, uma possível alteração nas características das águas subterrâneas é favorecida, ao passo que, quando os processos erosivos de alta intensidade prevalecem, como aqueles provocados pelo escoamento superficial, podem ocorrer alterações nas águas superficiais.

Nos últimos tempos, o governo federal se impôs um estímulo relevante à produção de álcool como combustível, iniciado com o Programa Nacional do Álcool (Proálcool) que, embora tenha sido criado em 1975, somente na década de 80, após o segundo choque do petróleo, em 1979, é que ocorreu um crescimento vigoroso em investimentos, subsídios e produtividade; em vista disto, as áreas de produção de cana-deaçúcar (Saccharum sp.) vêm aumentando continuamente, sobretudo na região Centro-Oeste do Brasil. Concomitantemente ao aumento da produção de álcool, é também acrescida a produção de vinhaça, um subproduto oriundo da sua fabricação. Para cada litro de álcool são produzidos de dez a dezoito litros de vinhaça, cuja composição é bastante variável dependendo principalmente da composição do vinho.

Quando depositada no solo, a vinhaça pode promover melhoria em sua fertilidade; todavia, quando usada para este fim, as quantidades não devem ultrapassar sua capacidade de retenção de íons, isto é, as dosagens devem ser mensuradas de acordo com as características de cada solo, uma vez que este possui quantidades desbalanceadas de elementos minerais e orgânicos, podendo ocorrer a lixiviação de vários desses íons, sobretudo do nitrato e do potássio.

Atualmente, a visão ambiental vem sendo enfatizada e, em alguns casos, a aplicação de vinhaça tem sido contestada pelos seus efeitos no solo e nas águas subterrâneas. Desta forma, a presente revisão propõe-se explorar os dados dis- poníveis sobre o tema, contribuindo para a discriminação dos efeitos benéficos e adversos sobre as propriedades químicas do solo e da água, causados pela aplicação de vinhaça. O levantamento bibliográfico realizado permitiu que se dividisse a abordagem em quatro tópicos básicos: características da vinhaça, alterações na composição química do solo, recarga do lençol freático e alterações nas propriedades das águas subterrâneas.

\section{CARACTERÍSTICAS DA VINHAÇA}

A vinhaça é o produto de calda na destilação do licor de fermentação do álcool de cana-de-açúcar; é líquido residual, também conhecido, regionalmente, por restilo e vinhoto. É produzida em muitos países do mundo como subproduto da produção de álcool; tendo em vista ser a matéria-prima diferente (cana-de-açúcar na América do Sul, beterraba na Europa etc.), a vinhaça apresenta diferentes propriedades. A concentração de sódio na vinhaça de cana-de-açúcar é menor que na de beterraba e elevados valores desse íon são indesejáveis já que podem causar condições nocivas ao solo e às plantas (Gemtos et al., 1999).

A vinhaça é caracterizada como efluente de destilarias com alto poder poluente e alto valor fertilizante; o poder poluente, cerca de cem vezes maior que o do esgoto doméstico, decorre da sua riqueza em matéria orgânica, baixo $\mathrm{pH}$, elevada corrosividade e altos índices de demanda bioquímica de oxigênio (DBO), além de elevada temperatura na saída dos destiladores; é considerada altamente nociva à fauna, flora, microfauna e microflora das águas doces, além de afugentar a fauna marinha que vem às costas brasileiras para procriação (Freire \& Cortez, 2000).

O constituinte principal da vinhaça é a matéria orgânica, basicamente sob a forma de ácidos orgânicos e, em menor quantidade, por cátions como o K, Ca e Mg, sendo que sua riqueza nutricional está ligada à origem do mosto. Quando se parte de mosto de melaço, apresenta maiores concentrações em matéria orgânica, potássio, cálcio e magnésio, ao passo que esses elementos decaem consideravelmente quando se trata de mosto de caldo de cana, como é o caso de destilarias autônomas (Rossetto, 1987). Dos efluentes líquidos da indústria sucroalcooleira, a vinhaça é a que possui maior carga poluidora, apresentando DBO variando de 20.000 a $35.000 \mathrm{mg} \mathrm{L}^{-1}$. A quantidade despejada pelas destilarias pode variar de 10 a $18 \mathrm{~L}$ de vinhaça por litro de álcool produzido, dependendo das condições tecnológicas da destilaria. A temperatura da vinhaça que sai dos aparelhos de destilação é de 85 a $90^{\circ} \mathrm{C}$ (Rossetto, 1987).

Vários estudos sobre a disposição da vinhaça no solo vêm sendo conduzidos, enfocando-se os efeitos no $\mathrm{pH}$ do solo, propriedades físico-químicas e seus efeitos na cultura da cana-de-açúcar mas poucos avaliaram o real potencial poluidor da vinhaça sobre o solo e lençol freático (Lyra et al., 2003) já que, em virtude dos elevados níveis de matéria orgânica e nutrientes, principalmente potássio, quase toda destilaria brasileira tem adotado sua utilização na fertirrigação de plantações de cana-de-açúcar (Cunha et al., 1981). 


\section{ALTERAÇÕES NA COMPOSIÇÃO QUÍMICA DO SOLO}

Glória \& Orlando Filho (1983) enumeraram os seguintes efeitos da vinhaça no solo: a) elevação do pH; b) aumento da disponibilidade de alguns íons; c) aumento da capacidade de troca catiônica (CTC); d) aumento da capacidade de retenção de água e) melhoria da estrutura física do solo. A vinhaça deve ser vista, também, como agente do aumento da população e atividade microbiana no solo. $\mathrm{O}$ pH dos solos tratados com vinhaça aumenta (Silva \& Ribeiro, 1998) principalmente em áreas cultivadas há mais tempo, embora nos primeiros dez dias após sua aplicação o pH sofra uma redução considerável para, posteriormente, elevar-se abruptamente, podendo alcançar valores superiores a sete; este efeito está ligado à ação dos microrganismos (Rossetto, 1987).

A matéria orgânica pode ser considerada fator importante na produtividade agrícola devido à influência que exerce sobre as propriedades químicas, físicas e biológicas do solo (Azeredo \& Manhães, 1983). No momento em que a matéria orgânica contida na vinhaça é incorporada ao solo, ela é colonizada por fungos, os quais a transformam em húmus, neutralizando a acidez do meio preparando, deste modo, o caminho para proliferação bacteriana; assim, quando adicionada como fertilizante, favorece também o desenvolvimento desses microrganismos os quais atuam na mineralização e imobilização do nitrogênio e na sua nitrificação, desnitrificação e fixação biológica, bem como de microrganismos participantes dos ciclos biogeoquímicos de outros elementos.

Segundo Neves et al. (1983) a adição de vinhaça, juntamente com a incorporação de matéria orgânica, pode melhorar as condições físicas do solo e promover maior mobilização de nutrientes, em função da também maior solubilidade proporcionada pelo resíduo líquido. Cunha et al. (1981) relatam que a dinâmica do nitrogênio no solo tratado com resíduos orgânicos, tal como a vinhaça, é complexa, devido às transformações bioquímicas. O nitrogênio está presente na vinhaça, predominantemente na forma orgânica, e a mineralização é a primeira transformação biológica que ocorre no solo. Uma vez que a relação $\mathrm{C} / \mathrm{N}$ na vinhaça é baixa, uma significante mineralização das formas imobilizadas de nitrogênio no solo pode ocorrer; contudo, Madejón et al. (2001) trabalhando com associação de vinhaça e outros materiais orgânicos no condicionamento do solo, observaram pequena elevação em sua salinidade, elevação no conteúdo de matéria orgânica e no nitrogênio total. Lyra et al. (2003), concordam com Madejon et al.(2001) ao sugerirem que se pode esperar uma elevação na concentração de sais no solo e potencial risco de salinização com a aplicação de vinhaça ao longo dos anos, considerando-se a taxa de absorção de potássio pela planta, sua concentração na vinhaça e a baixa condutividade elétrica (CE) observada no lençol freático, indicativo de reduzida lixiviação.

Ridesa (1994) observou que a eficiência da remoção da demanda bioquímica de oxigênio (DBO) pelo solo, pode ser afetada por sua capacidade de infiltração e pela presença de cobertura vegetal e, deste modo, quanto mais cobertura vegetal maior será a capacidade biológica de remoção. A eficiência da remoção da DBO tem sido constatada como eleva- da, mesmo em solos com alta capacidade de infiltração. Com relação ao nitrato, um dos maiores problemas citados na literatura acerca de contaminação de lençol freático, Madejón et al. (2001) observaram que, com a retirada da vegetação após cada colheita, os teores de nitrato se elevavam nos solos e concluíram que sua lixiviação abaixo da zona radicular pode ser desprezível quando esses compostos são aplicados em áreas vegetadas com emprego de práticas agrícolas adequadas, como a utilização de áreas afastadas de nascentes ou de regiões com lençol freático superficial.

Cunha et al. (1981) estudando a utilização de vinhaça como fertilizante e condicionador de solos, observaram que a acumulação de potássio no perfil não foi grande, ficando este elemento retido na camada de $0,50 \mathrm{~m}$ de profundidade, sendo que sua lixiviação foi pequena, acompanhando a drenagem interna no perfil.

Canellas et al. (2003) trabalhando em Cambissolo, não verificaram aumento de potássio nem cálcio em profundidade, tampouco da CTC ou nitrogênio; entretanto, observaram aumento nos teores de cobre e ferro na camada de 0,20-0,40 m de profundidade. Esses autores constataram, ainda, aumento na fração de ácidos fúlvicos de até 13\% na camada de $0,40 \mathrm{~m}$ o que poderia indicar tanto a evolução química dos compostos orgânicos como o transporte desta fração, para camadas de solo mais profundas.

\section{A RECARGA DO LENÇOL FREÁTICO}

Brouyère et al. (2004), a partir de observações de campo, concluem que os mecanismos de recarga dos lençóis freáticos e aqüíferos são controlados principalmente por fluxo gravitacional durante os eventos de chuva. Desta forma, o modo pelo qual a água se movimenta no planeta, as características de cada local e outros fenômenos, podem ser explicados pelo ciclo da água ou ciclo hidrológico.

O ciclo hidrológico representa o movimento da água no meio físico, podendo estar no estado gasoso, líquido ou sólido, distribuindo-se tanto na subsuperfície e superfície da Terra como na atmosfera; portanto, a água está em constante circulação passando de um meio a outro e de um estado físico a outro, sempre mantendo o equilíbrio, sem ganhos nem perdas de massa no sistema. Os processos que permitem esta circulação da água são: precipitação, interceptação, infiltração, evaporação, transpiração, absorção, retenção e detenção superficial, escoamento superficial, subsuperficial e subterrâneo; assim, a água evapora a partir dos oceanos e corpos d’água, áreas verdes, bem como do próprio solo, formando as nuvens que, em condições favoráveis, dão origem à precipitação, seja na forma de chuva, neve ou granizo.

A água pluvial, ao atingir o solo, pode escoar superficialmente até atingir os corpos d'água ou infiltrar até atingir o lençol freático e aquíf́ros; pode também abastecer diretamente os corpos d'água através da precipitação sobre eles. A capacidade de infiltração de água de um solo lhe é uma propriedade inerente e depende de sua granulometria, distribuição do tamanho de poros, umidade antecedente à chuva, condição superficial do solo e presença de adensamento subsuperficial; 
além disso, a água, interceptada e absorvida pela vegetação e outros seres vivos, retorna ao estado gasoso através da transpiração; este processo de interceptação tem grande importância na dissipação da energia cinética das gotas de chuva sobre o solo.

Estando o solo saturado ocorre a retenção superficial de água, a qual é dependente do microrrelevo superficial, rugosidade e da declividade do terreno. Quando todos os processos forem satisfeitos terá início o escoamento superficial. O escoamento depende da rugosidade hidráulica, declividade da área e da profundidade do fluxo (infiltração). Em razão disso, áreas com vegetação natural, principalmente florestas/matas, com relevo suave, solo estruturado com agregados estáveis e elevado volume de macroporos, tendem a gerar baixo escoamento superficial e elevada infiltração de água no solo, favorecendo a recarga do lençol freático e do aqüífero.

Uma bacia hidrográfica que contém cobertura de floresta natural não alterada caracteriza-se por sua capacidade inerente de diminuir as perdas de nutrientes pelo deflúvio; tal capacidade está relacionada frequentemente aos mecanismos de absorção de nutrientes pelas plantas e adsorção dentro do perfil do solo; ditos mecanismos agem no sentido de manter uma flutuação equilibrada da concentração iônica da água que drena da bacia e nela manter uma capacidade potencial de absorver a eventual entrada de nutrientes (Talsma et al., 1980); portanto, apresenta, em geral, uma ciclagem de nutrientes bastante equilibrada no que diz respeito ao balanço entre a entrada de íons via precipitação e a saída de íons via deflúvio, isto é, o assim chamado ciclo geoquímico de nutrientes (Lima, 1996).

\section{ALTERAÇÕES NAS PROPRIEDADES DAS ÁGUAS SUBTERRÂNEAS}

Estudos de monitoramento são conduzidos com a finalidade de se avaliar a sensibilidade do lençol freático e do aqüífero à contaminação. Com bastante freqüência se utilizam métodos relativamente empíricos para diferenciar zonas no lençol freático da bacia hidrográfica, com respeito à sua vulnerabilidade a contaminações ocorrendo na superfície do solo. A vulnerabilidade, associada a um local na bacia, é tão maior quanto menor for o tempo de trânsito de um contaminante da fonte de poluição ao aqüífero, quanto menor também for a atenuação da concentração durante o trânsito no perfil ou, ainda, quando a duração da contaminação for potencialmente maior (Brouyère et al., 2004). Esses autores citam, por outro lado, que as variações no nível do lençol freático afetam a evolução da contaminação já que, durante períodos de elevação do nível freático, os contaminantes migram em profundidade no perfil do solo, na zona anteriormente insaturada, a qual é lavada após saturação induzindo a um aumento na concentração desses elementos na água subterrânea. Contrariamente, quando o nível freático baixa, a frente de contaminação é desconectada da zona saturada e as concentrações desses elementos diminuem. Ressalte-se que o lençol freático é uma significativa ou única fonte de água em regiões áridas; sua contaminação poderia, em razão das atividades agrícolas, colocar em risco severo a sobrevivência nesses ambientes hostis (Oren et al., 2004) mas esta contaminação é expressa, em geral, em aumento na salinidade e na concentração de nitrato, que é um poluente mineral comum das águas subterrâneas em áreas agrícolas. Cabe lembrar, aqui, que o excesso de água ocasiona lixiviação de sais para o lençol freático (Oren et al., 2004), ou seja, no caso do nitrato ocorre acúmulo no perfil do solo em períodos secos e pode haver também lixiviação em períodos chuvosos (Rimski-Khorsakov et al., 2004).

A vinhaça, largamente utilizada nas lavouras canavieiras possui, em grandes quantidades, elementos que, dependendo da concentração, segundo Meurer et al. (2000) se destacam como contaminantes de águas superficiais e subterrâneas, como o fosfato e o nitrato, respectivamente. Esses elementos, conforme Resende et al. (2002), têm gerado, nos últimos anos, grande preocupação acerca dos efeitos, principalmente do nitrato, na saúde da população humana e animal. Stevenson (1986) afirma que o impacto dos nitratos atinge não só a saúde humana e animal como, também, o crescimento (diminuto ou excessivo) das plantas e a qualidade do ambiente (eutrofização).

Na Austrália, elevadas concentrações de nitrato em águas subterrâneas têm sido identificadas em todos os estados e territórios sob diferentes usos de solo (Thorburn et al., 2003). Esses autores também concluíram que ocorrem elevadas concentrações de nitrato na água subterrânea da costa noroeste da Austrália, além de salinidade acima do limite recomendável; contudo, verificaram que nesta região uma das maiores fontes de contaminação era a utilização de fertilizantes minerais e, em apenas oito de 1031 poços, a maior fonte de contaminação era de origem orgânica.

Para o fósforo, que é adsorvido fortemente na fase sólida, não existem valores elevados ocorrendo no lençol freático. De acordo com Oren et al. (2004), o destino do potássio é determinado, em parte, pela troca de íons e adsorção pelas argilas; assim, o enriquecimento do lençol freático por potássio é esporádico; no entanto, Cunha et al. (1981) concluíram haver risco de poluição de águas subterrâneas por nitrato e potássio, uma vez que foram detectadas pequenas quantidades desses íons em profundidades superiores a 1,20 m.

Costa et al. (1999) observaram, em estudo realizado em colunas de solo, que após fertilização com nitrato de cálcio ocorreu certa defasagem entre a frente de umedecimento e a frente de contaminação, fato este atribuído à presença de cargas positivas no solo, favorecendo a adsorção de nitrato junto à fase sólida deste solo; o fenômeno, comum em solos com carga variável e altamente intemperizados, pode minimizar o impacto que o excesso de ânions poderia causar às águas mas Brouyère et al. (2004) estudando o solo de carga permanente e a água de um aqüífero na Bélgica, notaram que houve alta variação entre as concentrações de nitrato nos poços de monitoramento, as quais variaram de 10 a $217 \mathrm{mg} \mathrm{L}^{-1}$ sendo que as menores concentrações foram encontradas na profundidade de 9,50 m (18 $\left.\mathrm{mg} \mathrm{L}^{-1}\right)$. Esses autores sugerem que nesta área esteja ocorrendo uma migração de nitrato, para as camadas mais profundas, da ordem 
de 1,0 m ano-1; contudo, Gloeden et al. (1991) relataram, em estudos realizados no aqüífero Botucatu, que mesmo com doses crescentes de vinhaça a concentração de potássio foi mantida próxima do natural, nas profundidades de 2,90 e 4,50 m, enquanto os teores de carbono orgânico dissolvido (DOC) indicaram forte variação nas camadas mais profundas após a aplicação de vinhaça, o que os autores creditam à sua associação a componentes orgânicos da vinhaça, principalmente coloidais; entretanto, Lyra et al. (2003) observaram redução significativa na demanda química de oxigênio (DQO) ao longo do perfil fertirrigado com vinhaça, uma vez que os valores no resíduo in natura utilizado são muito mais elevados que os constatados no lençol freático.

Cambuim (1983), em experimento em colunas com amostras de Neossolo Quartzarênico e com duas doses de vinhaça, afirmou que a lixiviação de cálcio, magnésio e potássio, ocorreu quase na mesma proporção das doses aplicadas havendo, ainda, redução nos teores de micronutrientes no lixiviado quando o tempo de incubação da vinhaça no solo foi maior, ou seja, quanto maior o intervalo entre a aplicação de vinhaça e a ocorrência de chuvas, maior também será a adsorção de micronutrientes nos sítios de troca do solo.

Gloeden et al. (1991) concluíram que o cloro, carbono orgânico e nitrogênio presentes na vinhaça, são elementos passíveis de imposição de risco ambiental no uso agronômico em solos e sedimentos permeáveis. Lyra et al. (2003) observaram escoamento superficial da vinhaça aplicada aos diferentes tipos de solo avaliados e, ainda, que após fertirrigação os valores medidos de CE no lençol freático não indicaram variações significativas mas, sim, eficiência do sistema solo na retenção de íons contidos na vinhaça. Esses autores concluíram que, como a avaliação da qualidade da água engloba uma série de parâmetros a serem contemplados com as devidas concentrações permitidas pela legislação, o impacto sobre a qualidade da água do lençol foi consideravelmente minimizado, mas não o suficiente para garantir o atendimento de todas as exigências ambientais.

\section{LEGISLAÇÃO AMBIENTAL}

Nos últimos anos, o Homem tem utilizado, com muita voracidade, os recursos naturais e, em virtude disso, existe fartura de alimentos, combustíveis e tecnologia, capazes de salvar vidas. Em contrapartida, tem ocorrido intensa degradação do ambiente com diminuição da biodiversidade, contaminação das fontes de água e do solo, entre outros (Schelp, 2005). Quando a população cresce em decorrência do sucesso da sociedade, a pressão por alimento se torna excessiva para os recursos naturais. O resultado é a fome, que leva à desagregação social e à guerra civil. Com vistas a esses fatos, foram elaborados decretos, leis e normas que têm, por finalidade, resguardar os recursos naturais.

Segundo Abreu Júnior et al. (2005) há muitos anos os resíduos das atividades humanas vêm sendo utilizados na agricultura; entretanto, com seu uso cada vez mais intenso cresceu também a preocupação da população com relação à segurança ambiental de forma que vem sendo elaborada le- gislação para a normatização do uso desses resíduos na agricultura.

Embora o Brasil ainda não possua uma política nacional específica para o uso de resíduos (Abreu Júnior et al., 2005) já existem algumas leis e decretos que devem ser obedecidos para a utilização de resíduos agroindustriais na agricultura da região; deste modo, podem ser citados o código das águas (Decreto 24.643 de 10 de Julho de 1934) que, entre outros, resguarda os corpos d’água contra a disposição de poluentes; o código florestal (Lei 4.771 de 15 de Setembro de 1965) que, dentre outras providências, fixa o limite mínimo de $20 \%$ de cobertura arbórea na parte Sul da região Centro-Oeste e dita, conforme o Art. $2^{\circ}$, as larguras mínimas das faixas de mata ciliar, de acordo com a largura dos cursos d'água, não permitindo, assim, que grandes plantações sejam locadas em suas margens e nas nascentes, visando à minimização de problemas de contaminação das águas.

Existe, ainda, a lei de crimes ambientais (Lei 9.605, de 12 de Fevereiro de 1998) a qual impõe as sanções penais a serem aplicadas em decorrência de lesão ao meio ambiente. No caso específico de efluentes, a referida lei, abraça, em seus artigos 33 e 54, os pontos mais importantes, em que são esclarecidas quais penas serão impostas aos infratores quando da ocorrência da morte de animais por emissão de efluentes nas águas e na ocorrência de poluição hídrica, respectivamente, caso em que os infratores recebem as penas de reclusão de um a três anos ou multa, ou ambas, cumulativamente, para infração do artigo 33 e de um a cinco anos de reclusão na infração do artigo 54. Para o caso específico da vinhaça existem, ainda, a Portaria do Ministério do Interior n. 323 de 29/11/1978, que dita que, a partir da safra 1979/ 1980, fica proibido o lançamento direto ou indireto, do vinhoto, em qualquer coleção hídrica, pelas destilarias de álcool instaladas ou que venham a se instalar no País; a Portaria do Ministério do Interior n. 158 de 03/11/1980, que dispõe sobre seu lançamento em coleções hídricas e sobre efluentes de destilarias de usinas de açúcar; a Resolução do CNRH n. 15 de 01/06/2001, que dá as diretrizes para a gestão integrada das águas superficiais, subterrâneas e meteóricas; a Portaria do Ministério da Saúde n. 518/04 de 25/03/ 2004, que estabelece procedimentos e responsabilidade relativos ao controle e vigilância da qualidade da água para consumo humano e seu padrão de potabilidade, além de outras providências. Existe, ainda, a Lei n. 9.605, de 12/02/98, que dispõe sobre as sanções penais e administrativas derivadas de condutas e atividades lesivas ao meio ambiente; a Lei $\mathrm{n}$. 7.960, de 21/12/89, que dispõe sobre a prisão temporária para crime de envenenamento de água potável, dentre outros; o Decreto-Lei n. 1.413, de 14/08/75, que dispõe sobre o controle da poluição do meio ambiente provocada por atividades industriais; a Portaria do Ministério do Interior n. 124, de 20/08/80, que baixa normas no tocante à prevenção de poluição hídrica, para a localização de indústrias, construções ou estruturas potencialmente poluidoras e para dispositivos de proteção. E, finalmente, a mais recente resolução do CONAMA n. 357, de 17 de março de 2005, que dispõe sobre a classificação dos corpos de água e diretrizes ambientais para o seu enquadramento, e estabelece, ainda, as 
condições e padrões de lançamento de efluentes e dá outras providências. E, conforme seu $\S 4^{\circ}$, estabelece as condições de lançamento de efluentes e, no $\S 5^{\circ}$, que regulamenta os padrões de lançamento de efluentes, que são:

$\mathrm{I}-\mathrm{pH}$ entre 5 a 9

II - temperatura: inferior a $40{ }^{\circ} \mathrm{C}$, sendo que a variação de temperatura do corpo receptor não deverá exceder a $3{ }^{\circ} \mathrm{C}$ na zona de mistura

III - materiais sedimentáveis: até $1 \mathrm{~mL} \mathrm{~L} \mathrm{~L}^{-1}$ em teste de $1 \mathrm{~h}$ em cone Imhoff. Para o lançamento em lagos e lagoas, cuja velocidade de circulação seja praticamente nula, os materiais sedimentáveis deverão estar virtualmente ausentes

IV - regime de lançamento com vazão máxima de até $1 / 2$ vez a vazão média do período de atividade diária do agente poluidor, exceto nos casos permitidos pela autoridade competente

$$
\begin{aligned}
& \text { V - óleos e graxas } \\
& 1 \text { - óleos minerais: até } 20 \mathrm{mg} \mathrm{L}^{-1} \\
& 2 \text { - óleos vegetais e gorduras animais: até } 50 \mathrm{mg} \mathrm{L}^{-1} \\
& \text { VI - ausência de materiais flutuantes }
\end{aligned}
$$

Tabela 1. Padrões para o lançamento de efluentes

\begin{tabular}{lc}
\hline Parâmetros & $\begin{array}{c}\text { Valor máximo } \\
\text { (mg L-1) }\end{array}$ \\
Inorgânicos & $0,50 \mathrm{As}$ \\
\hline Arsênio total & $5,00 \mathrm{Ba}$ \\
Bário total & $5,00 \mathrm{~B}$ \\
Boro total & $0,20 \mathrm{Cd}$ \\
Cádmio total & $0,50 \mathrm{~Pb}$ \\
Chumbo total & $0,20 \mathrm{CN}$ \\
Cianeto total & $1,00 \mathrm{Cu}$ \\
Cobre dissolvido & $0,50 \mathrm{Cr}$ \\
Cromo total & $4,00 \mathrm{Sn}$ \\
Estanho total & $15,00 \mathrm{Fe}$ \\
Ferro dissolvido & $10,00 \mathrm{~F}$ \\
Fluoreto total & $1,00 \mathrm{Mn}$ \\
Manganês dissolvido & $0,01 \mathrm{Hg}$ \\
Mercúrio total & $2,00 \mathrm{Ni}$ \\
Níquel total & $20,00 \mathrm{~N}$ \\
Nitrogênio amoniacal total & $0,10 \mathrm{Ag}$ \\
Prata total & $0,30 \mathrm{Se}$ \\
Selênio total & $1,00 \mathrm{~S}$ \\
Sulfeto & $5,00 \mathrm{Zn}$ \\
Zinco total & 1,00 \\
Orgânicos & 1,00 \\
Clorofórmio & $0,50 \mathrm{C} 6 \mathrm{H}{ }_{5} \mathrm{OH}$ \\
Dicloroeteno & 1,00 \\
Fenóis totais (substâncias que reagem com aminoantipirina) & 1,00 \\
Tetracloreto de Carbono & \\
Tricloroeteno & \\
\hline & \\
\hline
\end{tabular}

\section{CONCLUSÕES}

1. Embora a bibliografia acerca dos efeitos da vinhaça no solo e nas águas subterrâneas seja ainda bastante limitada, com poucos trabalhos com vinhaça de cana-de-açúcar e de beterraba, é possível verificar que os resultados são bastante variáveis em razão da grande diversidade de solos e composição das vinhaças.
2. Verificou-se unanimidade em relação à dosagem aplicada que apresentaria menores chances de contaminação de águas subterrâneas devendo ser relacionada ao tipo e condições do solo local, isto é, de acordo com o conteúdo de matéria orgânica, classe textural, existência de vinhaça residual, uma vez que esses exercem influência sobre a CTC e capacidade de armazenamento e infiltração de água no solo, além da profundidade do lençol freático, proximidade de nascentes e intensidade de atividade vegetal na área.

\section{LITERATURA CITADA}

Abreu Júnior, C. H.; Boaretto, A. E.; Muraoka, T.; Kiehl, J. C. Uso agrícola de resíduos orgânicos potencialmente poluentes: propriedades químicas do solo e produção vegetal. Tópicos Especiais em Ciência do Solo, Viçosa, v.4, p.391-470, 2005.

Azeredo, D. F.; Manhães, M. S. Adubação orgânica. In: Orlando Filho, J. (ed.). Nutrição e adubação da cana de açúcar no Brasil. Piracicaba:IAA/Planalsucar, 1983, p.227-264.

Brouyère, S.; Dassargues, A.; Hallet, V. Migration of contaminants through the unsaturated zone overlying the Hesbaye chalky aquifer in Belgium: A field investigation. Journal of Contaminant Hydrology, v.72, n.1-4, p.135-164, 2004.

Cambuim, F. A. A ação da vinhaça sobre a retenção de umidade, pH, acidez total, acumulação e lixiviação de nutrientes em solo arenoso. Recife: UFRPE, 1983. 133p. Dissertação Mestrado

Canellas, L. P.; Velloso, A. C. X.; Marciano, C. R.; Ramalho, J. F. G. P.; Roumjanek, V. M.; Rezende, C. E.; Santos, G. A. Propriedades químicas de um Cambissolo cultivado com cana-de-açúcar, com preservação de palhiço e adição de vinhaça por longo tempo. Revista Brasileira de Ciência do Solo, Viçosa, v.27, n. 5, p.935-944, 2003.

Costa, S. N.; Martinez, M. A.; Matos, A. T.; Ramos, V. B. N. Mobilidade do nitrato em colunas de solo sob condições de escoamento não permanente. Revista Brasileira de Engenharia Agrícola e Ambiental, v.3, n.2, p.190-194, 1999.

Cunha, R. C. A.; Costa, A. C. S.; Maset Filho, B.; Casarini, D. C. P. Effects of irrigation with vinasse and dynamics of its constituents in the soil: I - physical and chemical aspects. Water Science Technology, v.19, n.8, p.155-165, 1981.

Freire, W. J.; Cortez, L. A. B. Vinhaça de cana-de-açúcar. Guaíba: Agropecuária, 2000. 203p.

Gemtos, T. A.; Chouliaras, N.; Marakis, S. Vinasse rate, time of application and compaction effect on soil properties and durum wheat crop. Journal of Agriculture and Engineering Research, v.73, n.3, p.283-296, 1999.

Gloeden, E.; Cunha, R. C. A.; Fraccaroli, M. J. B.; Cleary, R. $\mathrm{W}$. The behaviour of vinasse constituents in the unsaturated and saturated zones in the Botucatu aquifer recharge area. Water Science Technology, v.24, n.11, p.147-157, 1991.

Glória, N. A.; Orlando Filho, J. Aplicação de vinhaça como fertilizante. São Paulo: Coopersucar, 1983. 38p.

Lima, W. P. Impacto ambiental do eucalipto. 2.ed. São Paulo: EDUSP, 1996. 301p. 
Lyra, M. R. C. C.; Rolim, M. M.; Silva, J. A. A. Toposseqüência de solos fertirrigados com vinhaça: contribuição para a qualidade das águas do lençol freático. Revista Brasileira de Engenharia Agrícola e Ambiental, v.7, n.3, p.525-532, 2003.

Madejón, E.; Lopez, R.; Murillo, J. M.; Cabrera, F. Agricultural use of three (sugar-beet) vinasse composts: effect on crops and chemical properties of a Cambisol soil in the Guadalquivir river valley (SW Spain). Agriculture, Ecosystems and Environment, v. 84, n.1, p.55-65, 2001.

Meurer, E. J.; Bissani, C. A.; Selbach, P. A. Poluentes do solo e do ambiente. In: Meurer, E. J. (ed.). Fundamentos de química do solo. Porto Alegre:Genesis, 2000, v.1, p.151-168.

Neves, M. C. P.; Lima, I. T.; Dobereiner, J. Efeito da vinhaça sobre a microflora do solo. Revista Brasileira de Ciência do Solo, Campinas, v.7, n.2, p.131-136, 1983.

Oren, O.; Yechieli, Y.; Boehlke, J. K.; Dody, A. Contamination of groundwater under cultivated fields in an arid environment, Central Arava Valley, Israel. Journal of Hydrology, v.209, n.34, p.312-328, 2004.

Resende, M.; Curi, N.; Rezende, S. B.; Corrêa, G. F. Pedologia: base para distinção de ambientes. 4.ed. Viçosa: NEPUT, 2002. 338p.

Ridesa, R. I. P. O. D. S. Aspectos ambientais da aplicação de vinhaça no solo. São Paulo: UFSCar, 1994. 67p.
Rimski-Khorsakov, H.; Rubio, G.; Lavado, R. S. Potential nitrate losses under different agricultural pratices in Pampas regions, Argentina. Agriculture Water Management, v.65, n.2, p.83-94, 2004.

Rossetto, A. J. Utilização agronômica dos subprodutos e resíduos da indústria açucareira e alcooleira. In: Paranhos, S.B. (ed.). Cana-de-açúcar: cultivo e utilização. Campinas:Fundação Cargill, 1987, v.2, p.435-504.

Schelp, D. A cegueira das civilizações. Veja, v.38, n.36, p.102-108, 2005.

Silva, A. J. N.; Ribeiro, M. R. Caracterização de um Latossolo Amarelo sob cultivo contínuo de cana-de-açúcar no Estado de Alagoas: propriedades químicas. Revista Brasileira de Ciência do Solo, v.22, n.2, p.291-299, 1998.

Stevenson, F. J. Cycles of sil-carbon, nitrogen, phosphorus, sulfur, micronutrientes. In: Tan, K.H. (Ed.). Principles of soil chemistry. 2.ed. New York:Marcell Dekker, 1986, 362p.

Talsma, T.; Mansell, R. S.; Hallam, P. M. Potassium and chloride movement in a forest soil under simulated rainfall. Australian Journal of Soil Research, v.18, n.3, p.333-342, 1980.

Thorburn, P. J.; Biggs, J. S.; Weier, K. L.; Keating, B. A. Nitrate in groundwater of intensive agricultural areas in coastal Northeastern Australia. Agriculture, Ecosystems and Environment, v.94, n.1, p.49-58, 2003. 